\title{
PATOGENESIS DAN DIAGNOSIS SINDROM KOLON IRITABEL
}

\author{
Edwin Jim \\ Bagian Ilmu Penyakit Dalam Fakultas Kedokteran Universitas Sam Ratulangi Manado \\ Email: edwinjim@yahoo.com
}

\begin{abstract}
Irritable bowel syndrome (IBS) is a chronic functional bowel disorder characterized by abdominal pain or discomfort and alterations in bowel habits. Many factors play some important roles in the development of the IBS including abnormal motility, visceral hypersensitivity, and enteric infection. Diagnosis of IBS is based on Rome III criteria.
\end{abstract}

Keywords: irritable bowel syndrome, pathogenesis, diagnosis

\begin{abstract}
Abstrak: Sindrom kolon iritabel (SKI) adalah penyakit gastrointestinal fungsional kronik yang ditandai oleh nyeri perut atau rasa tidak enak di perut dan gangguan kebiasaan defekasi. Banyak faktor yang menyebabkan terjadinya SKI antara lain gangguan motilitas, hipersensitivitas viseral, dan pasca infeksi usus. Saat ini kriteria diagnosis yang digunakan untuk SKI ialah kriteria Roma III.
\end{abstract}

Kata kunci: sindrom kolon iritabel, patogenesis, diagnosis

Sindrom kolon iritabel (SKI) adalah penyakit gastrointestinal yang ditandai oleh kebiasaan defekasi yang terganggu dan nyeri perut tanpa adanya kelainan struktural. ${ }^{1}$ SKI merupakan penyakit gastrointestinal fungsional yang sering dihadapi, dan diperkirakan terjadi pada $15 \%$ orang dewasa di negara Barat. $^{2-4}$ Istilah SKI pertama kali dijelaskan oleh Osler pada tahun $1892 .^{2}$

Walaupun bukan penyakit yang mengancam jiwa, SKI menyebabkan kesulitan pada pasien. SKI merupakan penyakit dismotilitas dari saluran gastrointestinal dengan dasar psikosomatik oleh karena pasien menunjukkan sejumlah gejala ketidaknyamanan tanpa kelainan organik. ${ }^{5}$ Oleh karena itu, SKI menyebabkan kehilangan produktivitas kerja dan kualitas hidup dapat memburuk. ${ }^{6}$

Etiologi dan patologi fungsional SKI belum diketahui secara pasti. ${ }^{5}$ Gejala SKI yaitu nyeri dan rasa tidak nyaman di perut yang membaik dengan defekasi, frekuensi defekasi yang abnormal, dan perubahan bentuk feses. ${ }^{2}$ Tidak terdapat prosedur diag- nosis spesifik untuk mengidentifikasi SKI karena patofisiologi dasar belum diketahui. Jadi, diagnosis tergantung pada kelompok gejala dan eksklusi penyakit patologis terkait. $^{5}$ Keraguan dalam menetapkan sindrom ini, kekurangan pemahaman patofisiologi, dan kekurangan bukti manfaat terapi menyebabkan SKI sulit didiagnosis dan diobati. ${ }^{2}$

\section{DEFINISI}

SKI merupakan suatu penyakit fungsional gastrointestinal yang kompleks, multifaktorial dan mempunyai manifestasi klinik berupa nyeri perut atau rasa tidak enak di perut serta gangguan kebiasaan defekasi. ${ }^{7,8}$ Penyakit fungsional adalah kondisi dimana tidak terdapat kelainan anatomi dan biokimia pada tes diagnostik. $^{1,5,8}$

\section{EPIDEMIOLOGI}

Angka kejadian SKI berkisar 9-23\% diseluruh dunia. ${ }^{8}$ Sekitar $15 \%$ penduduk 
Amerika mengalami SKI. Penyakit ini sering didiagnosis pada dewasa muda mulai umur 20 sampai 50 tahun. Ras kulit putih lebih sering mengalami SKI dibandingkan kulit berwarma. ${ }^{5}$ Jenis kelamin mempunyai peranan penting pada SKI dimana ratio antara perempuan dan laki-laki 2-3:1. ${ }^{9}$ Choudhary dan Truelove melaporkan di negara Barat rasio SKI perempuan dan laki-laki 2:1 dan di Amerika $3: 2 .^{5}$ Di pedesaan, angka kejadian lebih sedikit dibandingkan diperkotaan. ${ }^{10}$

Biaya kesehatan untuk SKI di Amerika Serikat diperkirakan 8 juta dolar sebagai biaya medis dan 25 juta dolar sebagai biaya tidak langsung setiap tahun. ${ }^{2,4,5}$

\section{ETIOPATOGENESIS}

Penyebab SKI tidak diketahui, tidak terdapat kelainan anatomi yang ditemukan, ${ }^{11}$ serta tidak ada patofisiologi yang pasti. ${ }^{12}$ Faktor emosional, diet, atau hormon dapat mencetuskan atau memperburuk gejala. $^{11}$

Sejumlah penelitian dan publikasi ilmiah tentang etiologi dan patofisiologi SKI telah berkembang dalam beberapa dekade terakhir. ${ }^{7}$ Sampai saat ini tidak ada teori yang menyebutkan bahwa SKI disebabkan oleh satu faktor saja. ${ }^{9}$ Banyak faktor yang menyebabkan terjadinya SKI, antara lain gangguan motilitas, hipersensitivitas viseral, dan pasca infeksi usus. ${ }^{9}$ Sebaiknya SKI dipahami sebagai suatu integrasi beberapa faktor terkait sebagai berikut: ${ }^{12}$

\section{Motilitas abnormal}

Motilitas abnormal terdapat SKI predominan diare dan SKI predominan konstipasi yang menunjukkan bahwa pada SKI terjadi suatu perubahan motilitas. ${ }^{9}$ Pada SKI tipe diare terjadi peningkatan kontraksi usus dan memendeknya waktu transit kolon dan usus halus. Berbeda halnya pada SKI predominan konstipasi dimana terjadi penurunan kontraksi usus dan memanjangnya waktu transit kolon dan usus halus. ${ }^{2,5,9}$

Stres fisik atau psikologis dan makanan

tertentu dapat menganggu motilitas kolon. ${ }^{4}$ Makanan tinggi kalori dapat meningkatkan motilitas lambung. Makanan berlemak dapat menyebabkan aktivitas motorik terlambat, dan dapat memperburuk keadaan SKI. ${ }^{3-5}$ Pada hari-hari pertama menstruasi dapat terjadi peningkatan sementara dari prostaglandin E2, yang menyebabkan peningkatan nyeri dan diare. $^{1,11}$

\section{Hipersensitivitas viseral}

Hipersensitivitas viseral sering dihubungkan dengan SKI. Pasien SKI mengalami nyeri dan rasa kembung pada tekanan dan volum usus yang lebih rendah dibandingkan kontrol. Hal ini disebabkan sensitivitas reseptor di usus terganggu melalui nosiseptor sebagai respon terhadap iskemi, distensi, infeksi, makanan, atau faktor kejiwaan. ${ }^{4}$ Persepsi rektal terganggu ditemukan pada $62 \%$ penderita SKI. Gejala nyeri perut dan kembung dikaitkan dengan persepsi rektal terganggu. Gejala sering dihubungkan dengan jenis kelamin perempuan dan kecemasan. ${ }^{13}$ Pasien sering mempunyai ambang nyeri viseral rendah. Banyak pasien melaporkan rasa ingin defekasi segera walaupun volum feses sedikit. ${ }^{2,4}$ Dengan makan makanan berlemak, beberapa pasien mengeluhkan lebih nyeri karena nilai ambang nyeri menurun. Gejala setelah makan sebagai akibat peningkatan komponen sensorik dari gastrokolon yang tergantung nutrien. ${ }^{1}$ Stimulus nyeri dari usus dihantarkan oleh aferen spinal primer dalam ganglion akar dorsal ke kornu dorsal medula spinalis. Sinaps di kornu dorsal merupakan pintu masuk ke susunan saraf pusat.

Sinyal aferen yang berbahaya ke otak melalui dua jalur klasik, yaitu traktus spinotalamik dan traktus spinoretikular. Traktus spinotalamik atau sistem nyeri lateral bermanfaat membantu fungsi diskriminatif. Jalur spinotalamik membawa impuls aferen dari kornu dorsal medula spinalis ke talamus, kemudian ke korteks sensorik. Bagian korteks sensorik yang mengurusi sensasi somatik adalah girus presentral sedangkan sensasi viseral ditransmisikan ke insula, bagian lobus 
temporal. Korteks insular contohnya untuk mengode indera perasa dan indera penciuman pada binatang. ${ }^{14}$ Traktus spinoretikular membawa pesan aferen yang berbahaya ke sistem nyeri medial, yang mengode nyeri. Pada orang normal, nyeri distensi gaster berkaitan dengan aktivasi batang otak. Dari formasi retikular batang otak, stimuli asenden mencapai bagian medial talamus, selanjutnya mengaktivasi sistem limbik, terutama anterior cingulate cortex (korteks singulat anterior, ACC), yang mempunyai hubungan langsung dengan nukleus talamik intralaminar. ${ }^{14}$ Pada binatang, stimuli nyeri mengaktivasi talamus dan ACC. Telah diketahui bahwa ACC merupakan pusat penting pada nyeri somatik atau viseral, dan juga berkaitan dengan perhatian dan deteksi hal baru. Intensitas subjektif nyeri rektal dan nyeri somatik berkorelasi dengan aliran darah ACC. Dari sistem nyeri medial dan lateral, informasi akhirnya mencapai korteks prefrontal, dimana terdapat fungsi lebih tinggi seperti terjadinya interpretasi. ${ }^{14}$

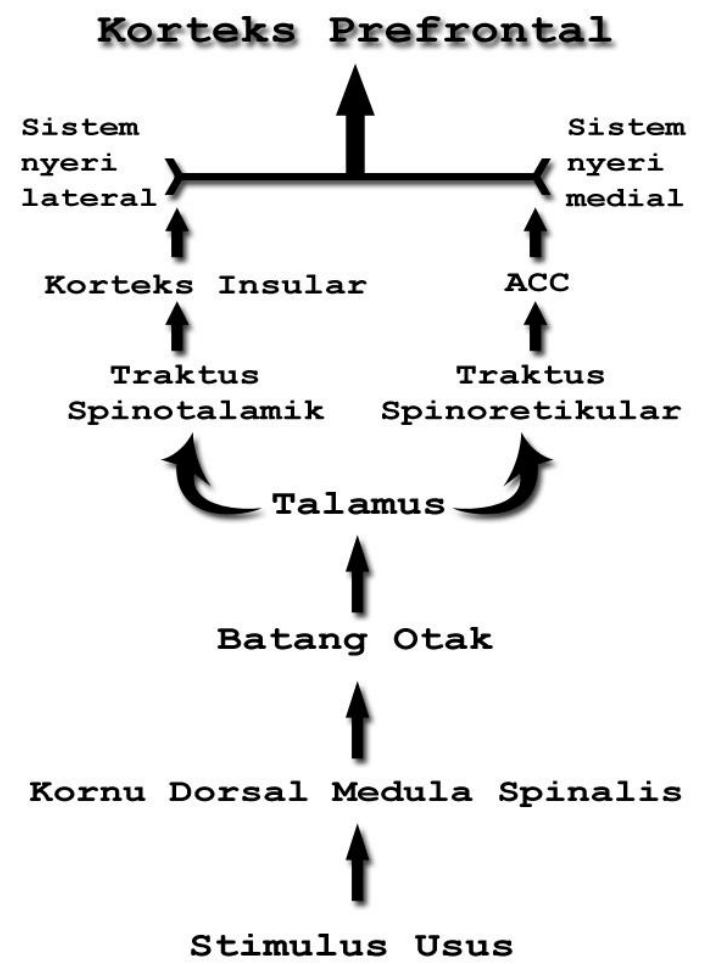

Gambar 1. Aksis otak-usus. Sumber: Mertz, $2002 .^{14}$
Pada distensi esofagus dan pengamatan Positron Emission Tomography (PET), Azis et al mendeteksi peningkatan aliran darah ke ACC, korteks prefrontal, talamus, dan lebih besar korteks insular. Peningkatan aliran darah ke ACC dan korteks prefrontal pada saat rangsangan nyeri dibandingkan tidak nyeri; hal ini mengindikasikan kedua daerah ini menerima fungsi nosiseptif viseral (nyeri dan tidak nyaman). ${ }^{14}$

Studi functional magnetic resonance imaging (fMRI) oleh Mertz menunjukkan peningkatan aliran darah ke korteks insular, talamus, korteks prefrontal, dan ACC selama distensi rektal nyeri dan tidak nyeri. Terdapat peningkatan relatif aliran darah di ACC, korteks prefrontal, dan talamus ketika rangsangan nyeri dibandingkan stimulus intensitas rendah. Aliran darah di ACC berkorelasi erat dengan intensitas nyeri subjektif; hal ini mendukung peranannya dalam proses nyeri. ${ }^{14}$ Mertz et al melakukan distensi rektal pada pasien SKI dan kontrol. fMRI digunakan untuk mengukur perubahan aliran darah serebral. Kontrol mempunyai tingkat aktivasi otak yang sama selama distensi $30 \mathrm{mmHg}$ (tidak nyeri) dan $55 \mathrm{mmHg}$ (nyeri). Pasien SKI mempunyai aktivasi talamus dan ACC yang lebih besar secara bermakna selama stimulus $55 \mathrm{mmHg}$ dibandingkan distensi $30 \mathrm{mmHg}$. Para pasien SKI mempunyai volumee aktivitas ACC lebih besar dibandingkan kontrol dengan stimuli nyeri. Selain itu pasien SKI kehilangan korelasi normal dari aktivasi ACC dan intensitas nyeri subjektif. $^{14}$

\section{Infeksi usus}

Setelah infeksi usus akut, sebagian besar pasien menunjukkan akselerasi transit gastrointestinal dan peningkatan sensitivetas usus. Hal ini akan kembali menjadi normal secara bertahap, tetapi masa pulih bervariasi. ${ }^{15}$ Permeabilitas usus meningkat pada kebanyakan pasien pasca gastroenteritis, biasanya berlangsung 6-12 minggu, malah pada beberapa pasien sampai 4 tahun. Peningkatan permeabilitas dipenga- 
ruhi oleh aktivasi sel mast. Stres menyebabkan degranulasi sel mast dan peningkatan permeabilitas usus. Granula sel mast mengandung mediator-mediator termasuk histamin, prostaglandin, dan serotonin, yang menyebabkan sensitisasi dan peningkatan fungsi sekreto-motorik. ${ }^{15}$ Inflamasi mukosa mengaktivasi sensitisasi dan hipermotilitas perifer sehingga menyebabkan terjadinya gejala $\mathrm{SKI}^{4}$ Sepertiga kasus SKI terjadi setelah infeksi, dimana keluhan SKI muncul satu bulan pasca infeksi. ${ }^{1,9}$ Pada perempuan dan pasien dengan stresor kehidupan yang tinggi saat onset gastroenteritis berisiko tinggi menjadi SKI pasca-infeksi. ${ }^{16}$ Degradasi karbohidrat oleh bakteri di usus halus dapat menyebabkan peningkatan gas setelah makan, kembung dan distensi, yang dapat membaik setelah pemberian antibiotik, tetapi studi lain meragukan penemuanpenemuan ini. ${ }^{16,17}$ Kuman penyakit SKI pasca infeksi antara lain campylobacter, salmonella, dan shigella. ${ }^{1}$

\section{Kelainan psikososial}

Kelainan psikososial dapat memicu gejala SKI. ${ }^{18}$ Kelainan psikiatrik ditemukan mencapai $80 \%$ pasien SKI, tanpa adanya diagnosis psikiatrik yang predominan. ${ }^{1}$ Beberapa pasien memperlihatkan ansietas, depresi atau somatosisasi, tetapi stres dan konflik emosional tidak selalu berkaitan dengan onset gejala dan rekurensi. ${ }^{5,11,10}$ Kelainan psikologik dapat mempengaruhi cara pasien menerima atau bereaksi terhadap penyakit dan sensasi viseral. Stres kronik dapat mengubah motilitas usus atau memodulasi jalur yang mempengaruhi proses spinal dan sentral dari sensasi aferen viseral. ${ }^{16}$

\section{Ketidakseimbangan neurotransmitter}

Ketidakseimbangan neurotransmitter, antara lain serotonin. Bahan ini terdapat dalam sistem saraf pusat sebesar $5 \%$, sedangkan sisanya $95 \%$ terdapat pada saluran cerna dalam sel enterokromafin, neuron, sel mast, dan sel otot polos. Ketika dilepaskan oleh sel enterokromafin, serotonin mensti- mulasi serat saraf aferen vagal ekstrinsik dan serat saraf aferen enterik intrinsik, yang menyebabkan respon fisiologik seperti refleks peristaltik dan sekresi usus. Pasien SKI mempunyai serotonin dalam plasma dan kolon yang lebih tinggi. ${ }^{4}$

\section{GEJALA KLINIS}

Penyakit SKI merupakan penyakit kronik. Gejala biasanya mulai pada umur belasan tahun atau dua puluhan. ${ }^{16}$ Onset pada dewasa lanjut tidak lazim tetapi juga tidak jarang. ${ }^{11}$ Gejala harus minimal 3 bulan sebelum diagnosis dipikirkan. Diagnosis ditegakkan berdasarkan gejala dan pemeriksaan penunjang untuk menyingkirkan penyakit organik. $^{16}$

Nyeri abdomen merupakan gejala utama SKI. Sifat nyeri bervariasi dalam intensitas dan lokasi. ${ }^{1}$ Nyeri abdomen dapat berupa kram, kolik, atau nyeri tumpul baik terus-menerus maupun intermiten pada perut bagian bawah. Onset nyeri khas berkaitan dengan perubahan frekuensi atau bentuk defekasi dan biasanya membaik dengan defekasi. Nyeri biasanya tidak terjadi pada malam hari atau sampai mengganggu tidur. ${ }^{1,3}$ Gejala dapat dirangsang oleh stres dan makanan. ${ }^{1,11}$ Pasien perempuan sering mengeluhkan gejala yang memburuk selama premenstruasi dan menstruasi. Kembung, nausea, dispepsia, dan pirosis juga dapat dikeluhkan. ${ }^{1,10}$

Pasien SKI dapat diklasifikasikan menjadi tiga kategori: pasien yang mempunyai masalah predominan konstipasi, diare, atau campuran konstipasi dan diare. Pasien SKI dengan konstipasi melaporkan defekasi yang jarang (kurang dari 3 kali/minggu), feses keras sehingga harus dipaksakan. Pasien SKI dengan diare ditandai diare yang timbul tiba-tiba sebelum, selama atau setelah makan, terutama bila makan terburu-buru; feses cair, defekasi sering (lebih dari tiga kali/hari), nyeri, kembung, urgensi, atau inkontinensia fekal. Feses juga dapat disertai mukus. ${ }^{1,3,8}$ Diare tanpa nyeri tidak khas dan mengarahkan dokter untuk memikirkan kemungkinan diagnostik lain (misalnya malabsorpsi dan 
diare osmotik). ${ }^{11}$

Sifat dan lokasi nyeri, faktor pencetus, dan pola defekasi berbeda pada setiap pasien. Juga terdapat gejala ekstra-intestinal pada SKI, misalnya fibromialgia, sakit kepala, dispareunia, atau sindrom sendi temporomandibular. ${ }^{11}$

Pemeriksaan fisik harus dilakukan untuk mencari bukti adanya penyakit organik. Pada pasien SKI pemeriksaan fisik biasanya normal. Nyeri abdomen, terutama abdomen bagian bawah, sering dikeluhkan tetapi tidak berat. ${ }^{16}$ Onset yang baru pada pasien diatas 40 tahun memerlukan pemeriksaan lebih lanjut. ${ }^{3}$

\section{PEMERIKSAAN LABORATORIUM DAN PEMERIKSAAN KHUSUS}

Pasien dengan gejala yang memenuhi kriteria diagnostik SKI dan tanpa alarm symptoms, tidak memerlukan pemeriksaan diagnostik lanjutan, karena kemungkinan penyakit organik serius tidak ada. ${ }^{16}$ Tes penunjang sebaiknya lebih intensif bila terdapat alarm symptoms: onset umur lebih dari 40 tahun, berat badan menurun, perdarahan saluran gastrointestinal, demam, muntah, gejala timbul pada malam hari, riwayat keluarga menderita kanker, dan pada pemeriksaan fisik ditemukan anemia atau demam. ${ }^{9,19}$

Kecemasan pasien dapat mendorong dokter untuk mempertimbangkan berbagai pemeriksaan diagnostik tetapi pemeriksaan berlebihan harus dihindari. Pemeriksaan laboratorium skrining meliputi pemeriksaan darah (hitung darah lengkap, laju endap darah) dan analisis feses (telur cacing, parasit, dan darah). ${ }^{12}$ Pemeriksaan hormon tiroid sebaiknya dilakukan pada pasien dengan diare kronis yang menonjol. ${ }^{19}$

Proktosigmoidoskopi dengan instrumen fiberoptik fleksibel sebaiknya dilakukan. Masuknya sigmoidoskop dan insuflasi udara sering merangsang nyeri dan spasme usus. Pola vaskular dan mukosa pada SKI biasanya normal. ${ }^{11}$

Kolonoskopi atau enema barium pada pasien dengan gejala SKI tidak direkomendasikan pada pasien tanpa alarm symptoms atau hematologi atau kimia darah abnormal. Pada pasien dengan diare, tes serologi untuk penyakit Celiac dapat dilakukan. Pada semua pasien diatas 50 tahun atau lebih, enema barium atau kolonoskopi sebaiknya dipertimbangkan untuk menyingkirkan keganasan. ${ }^{11,16}$ Pada pasien dengan diare kronik, khususnya perempuan tua, biopsi mukosa dapat dilakukan untuk menyingkirkan kolitis. ${ }^{11}$

\section{DIAGNOSIS}

SKI merupakan penyakit tanpa kelainan patognomonik sehingga diagnosisnya berdasarkan gejala klinis dan eliminasi penyakit organik lain. ${ }^{1}$ Gejala yang dapat muncul pada pasien SKI cukup bervariasi. Pemeriksaan fisik dan laboratorium yang spesifik pada pasien SKI tidak ada, oleh karena itu penegakan diagnosis SKI kadang kala tidak mudah. ${ }^{9}$ Sebelum memikirkan apakah pasien yang dihadapi adalah pasien SKI, perlu disingkirkan kemungkinan lain didasarkan pada adanya alarm symptoms. ${ }^{19}$

Kriteria yang digunakan saat ini ialah kriteria Roma III (Tabel 1) yang diluncurkan pada 23 Mei 2006, menggantikan kriteria Roma I dan II. $^{20,21}$

Tabel 1. Kriteria Roma III untuk SKI. dikutip dari 20

At least 3 months, with onset at least 6 months previously of recurrent abdominal pain or discomfort associated with two or more of the following:

- Improvement with defecation; and/or

- Onset associated with a change in frequency of stool; and/or

- Onset associated with a change in form (appearance) of stool.

Discomfort means an uncomfortable sensation not described as pain.

Selain kriteria Rome III, secara praktis sering juga digunakan kritera Manning yang lebih sederhana dan menitikberatkan pada keadaan saat onset nyeri antara lain 
adanya buang air besar cair dan peningkatan frekuensi defekasi saat timbulnya nyeri (Tabel 2). ${ }^{3,5,9}$

Sering pasien SKI dianjurkan melakukan pemeriksaan penunjang berlebihan. ${ }^{11}$ Pemeriksaan laboratorium tambahan tidak membuat diagnosis lain pada pasien yang memenuhi kriteria Roma. ${ }^{4,11}$ Suatu penelitian validasi kriteria Roma menunjukkan bahwa $100 \%$ pasien yang didiagnosis SKI berdasarkan kriteria Roma memang mengalami SKI. Pada pemantauan 2 tahun, tidak ada pasien SKI yang mengalami perubahan diagnosis. $^{8}$

\section{DIAGNOSIS BANDING}

Sejumlah penyakit dapat mempunyai gejala yang sama; sebagai contoh, neoplasia kolon, inflammatory bowel disease (kolitis ulserativa, penyakit Crohn, kolitis mikroskopik), hipertiroid atau hipotiroid, investasi parasit, malabsorpsi, penyebab diare sekretori kronik, obstruksi mekanik kolon, dan endometriosis. ${ }^{4,12,16}$ Penyakit psikiatrik seperti depresi, gangguan panik, dan ansietas juga harus dipertimbangkan. Pasien perempuan dengan gejala refrakter mempunyai insidens yang tinggi akibat perlakuan kasar fisik dan seksual. ${ }^{12,16}$ Pada pasien tanpa alarm symptoms, adanya penyakit organik sangat tidak mungkin. ${ }^{4}$

Tabel 2. Kriteria Manning. ${ }^{9}$

Gejala yang sering didapat pada penderita SKI yaitu:

- Feses cair pada saat nyeri

- Frekuensi buang air besar bertambah pada saat nyeri

- Nyeri berkurang setelah buang air besar

- Tampak abdomen distensi

Dua gejala tambahan yang sering muncul pada pasien SKI:

- Lendir saat buang air besar

- Perasaan tidak lampias saat buang air besar

\section{PROGNOSIS}

Penyakit SKI tidak akan meningkatkan mortalitas. Pada 50\% kasus gejala-gejala biasanya akan membaik dan hilang setelah 12 bulan; kurang dari 5\% yang akan memburuk; dan sisanya dengan gejala yang menetap. ${ }^{9}$

\section{SIMPULAN}

Sindrom kolon iritabel (SKI) adalah penyakit gastrointestinal fungsional kronik yang ditandai oleh nyeri perut atau rasa tidak enak di perut dan gangguan kebiasaan defekasi. Banyak faktor yang menyebabkan terjadinya SKI antara lain gangguan motilitas, hipersensitivitas viseral, pasca infeksi usus, faktor psikososial dan ketidakseimbangan neurotransmiter. Kriteria diagnostik yang digunakan saat ini ialah kriteria Roma III. Penyakit ini tidak meningkatkan mortalitas dan 50\% akan membaik dan hilang setelah 12 bulan.

\section{DAFTAR PUSTAKA}

1. Owyang C. Irritable bowel syndrome. In: Kasper DL, Braunwald E, Fauci AS, Hauser AL, Longo DL, Jameson JL, et al, editors. Harrison's Principles of Internal Medicine (Sixteenth Edition). New York: McGraw-Hill, 2005; p.178993.

2. Grundfast MB, Komar MJ. Irritable bowel syndrome. JAOA. 2001;101:S1-5.

3. Turnbull GK, Vaner SJ, Burnstein M. The colon. In: First Principles of Gastroenterology (Third Edition). Ontario: Canadian Association of Gastroenterology, 1997; p.360-4.

4. Horwitz BJ, Fisher RS. The irritable bowel syndrome. N Engl J Med. 2001;344: 1846-9.

5. Singh RK, Pandey HP, Singh RH. Irritable bowel syndrome: Challenges ahead. Current Science. 2003;84: 1525-31.

6. Bracco A, Reilly MC, McBurney CR. Burden of irritable bowel syndrome with constipation on health care resource utilization, work productivity and activity impairment and quality of life. World Congress of Gastroenterology 
2005. Montreal: Pulsus Group, 2005; R.0652.

7. Spercer AD. The pathophysiology of irritable bowel syndrome. IMAJ. 2003; 5:18-3.

8. Chang L. Irritable bowel syndrome [homepage on the Internet]. 2007 [updated 2007; cited 2007 Jul 25. Available from: http://www.cns.med. ucla.edu/PDFs/ IBS ReviewArticle.pdf

9. Syam AF, Manan C. Sindrom kolon iritabel. In: Sudoyo AW, Setiyohadi B, Alwi I, Simadibrata M, Setiadi S, editors. Buku Ajar Ilmu Penyakit Dalam (Edisi Keempat). Jakarta: Departemen Ilmu Penyakit Dalam FKUI, 2006; p.383-5.

10. Mudjaddid E. Peran psikopatologi pada sindrom kolon iritabel: Seberapa penting? In: Simadibrata M, Syam AF, editor. Update in Gastroenterology 2005. Jakarta: Departemen Ilmu Penyakit Dalam FKUI, 2005; p.54-64.

11. Walfishh A. Irritable bowel syndrome. In: Porter RS, Beers MH, Jones TV, Kaplan JL, Berkwits M, editors. The Merck Manual of Medical Information (Second Edition). New York: Pocket Books Merck Research Laboratories, 2000; p. 688-9

12. Ringel Y, Drossman DA. Irritable bowel syndrome. In: Runge MS, Greganti MA, editors. Netter's Internal Medicine. New Jersey: Iron Learning System, 2005; p. 327-34.

13. Posserud I. Peripheral and central factors in the pathophysiology of irritable bowel syndrome. Goteborg: Department of
Internal Medicine The Sahlgrenska Academy at Göteborg University, 2007; p.2-62.

14. Mertz H. Altered CNS processing of visceral pain in IBS. In: Camilleri M, Spiller R, editors. Irritable Bowel Syndrome Diagnosis and Treatment. London: WB Saunders, 2002; p.55-67.

15. Spiller RC. Post-infectious IBS. In: Camilleri M, Spiller R, editors. Irritable Bowel Syndrome Diagnosis and Treatment. London: WB Saunders, 2002; p.85-94.

16. McQuaid KR. Irritable bowel syndrome. In: McPhee SJ, Papadakis MA, Tierney LM, editors. Current Medical Diagnosis \& Treatment 2007. New York: McGraw-Hill, 2007; p.628-32.

17. Marshall JK, Thabane M, Garg AX. Post-infectious irritable bowel syndrome after the Walkerton outbreak of waterborne gastroenteritis. World Congress of Gastroenterology 2005. Montreal: Pulsus Group, 2005; R.0641.

18. Amiriani T, Pourshams A, Semnani S. Relation of irritable bowel syndrome and psychological disorders in freshmen of Tehran University. World Congress of Gastroenterology 2005. Montreal: Pulsus Group, 2005; R.0642.

19. Rani A, Syam AF. Diagnosis sindrom kolon iritabel: Masalah Praktis dengan kriteria diagnosis. In: Simadibrata M, Syam AF, editors. Update in Gastroenterology 2005. Jakarta: Departemen Ilmu Penyakit Dalam FKUI, 2005; p.49-53. 